\title{
A sexualidade como uma construção cultural: reflexões sobre preconceitos e mitos inerentes a um grupo de mulheres rurais
}

\author{
SEXUALITY AS A CULTURAL CONSTRUCTION: REFLEXIONS ON INHERENT PREJUDICEAND MYTHS ONA \\ GROUP OF WOMEN IN RURAL AREAS \\ LA SEXUALIDAD COMO UNA CONSTRUCCIÓN CULTURAL: REFLEXIONES SOBRE PREJUICIOS Y MITOS
INHERENTES A UN GRUPO DE MUJERES RURALES
}

Lúcia Beatriz Ressel',Dulce Maria Rosa Gualda ${ }^{2}$

1 Doutora, Professora Assistente do Departamento de Enfermagem da Universidade Federal de Santa Maria (UFSM) Ibressel@bol.com.br

2 Doutora, Professora Associada do Departamento de Enfermagem MaternoInfantil e Psiquiátrica da Escola de Enfermagem da USP (EEUSP).

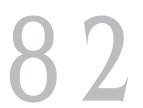

Rev Esc Enferm USP 2003; 37(3): 82-7.

\author{
RESUMO \\ Este artigo apresenta a \\ sexualidade como uma \\ construção cultural. Para \\ fundamentar tal assertiva, é \\ relatada uma pesquisa \\ realizada com um grupo de \\ onze mulheres de uma \\ comunidade rural, no interior \\ do Rio Grande do Sul. Os \\ dados foram coletados por \\ meio de entrevistas semi- \\ estruturadas e as narrativas \\ foram analisadas \\ qualitativamente, buscando, \\ via ótica cultural, o \\ significado dos depoimentos. \\ A sexualidade é, aqui, \\ contemplada a partir das \\ vivências individuais, dos \\ valores, das crenças, dos \\ mitos e dos preconceitos, \\ construídos ao longo da \\ socialização de cada \\ colaboradora. No final do \\ texto, foram acrescentadas \\ algumas reflexões que \\ salientam a importância de \\ tal interpretação cultural \\ sobre os eventos, \\ especialmente sobre a \\ sexualidade para as \\ enfermeiras.
}

\section{PALAVRAS-CHAVE}

Sexualidade.

Cultura.

Pesquisa.

\section{ABSTRACT}

The present work focuses on sexuality as a cultural construct. To support this idea, a study was carried out with a group of eleven women from a rural community, in the countryside of Rio Grande do Sul, Brazil. The data was collected through semistructured interviews and the narratives were analyzed qualitatively, seeking to extract meaning from the inquiries by viewing them through a cultural lens. Sexuality is viewed as a personal experience, composed of values, beliefs, myths and prejudice assimilated during the socialization of each respondent. Reflections highlighting the importance of cultural interpretation of the events for nurses, especially those referring to sexuality to the nurses, were included.

KEYWORDS

Sexuality.

Culture.

Research

\begin{abstract}
RESUMEN
Este artículo enfoca la sexualidad como una construcción cultural. Para fundamentar tal aseveración, se relata la búsqueda realizada con un grupo de once mujeres de una comunidad rural, en el interior de Rio Grande do Sul. Los datos fueron recolectados através de entrevistas semiestructuradas y las narrativas analizadas cualitativamente, buscando, vía óptica cultural, el significado de los relatos. La sexualidad, aquí, es contemplada a partir de las vivencias individuales, de los valores, de las superstición, de los mitos y de los prejuicios, construídos a lo largo de la socialización de cada colaboradora. Al final del texto, fueron agregadas algunas reflexiones que resaltan la importancia de tal interpretación cultural sobre los eventos, especialmente sobre la sexualidad para las enfermeras.
\end{abstract}

\section{PALABRAS-CLAVE}

Sexualidad.

Cultura.

Investigacion. 


\section{INTRODUÇÃO}

Este artigo aborda a sexualidade como uma construção cultural. Esta, tratada de forma interdisciplinar em um evento ${ }^{(a)}$; propiciou momentos de reflexão, nos quais diferentes pontos de vista e leituras sobre o fenômeno puderam ser socializados, descortinando horizontes até então encobertos para muitos participantes. Esse fórum de discussão possibilitou, ao mesmo tempo, desvelar o referido tema da "invisibilidade" e do "ocultamento", em que tal fenômeno está alocado dentro da área da saúde.

Os termos "invisibilidade" e "ocultamento" são empregados, neste texto, em referência à permeabilidade da sexualidade, enquanto foco de discussão, de reflexão e de estudos, dentro do espaço acadêmico, no mesmo sentido de "ausência", utilizado por Figueiredo $^{(1)}$, quando se refere à representação assexuada do corpo da enfermeira, assim elaborada por muitas pessoas.

$\mathrm{Na}$ área da saúde, tanto na prática quanto no ensino, em que constantemente interagem corpos sexuados (os das enfermeiras e os dos alunos ou paciente), inúmeras vezes, é negada a existência da sexualidade, que se expressa a todo momento, através de gestos, olhares, sentimentos, silêncios, posturas, concepções e traz significações que são insinuadas muito mais do que são externadas ${ }^{(2)}$.

Assim como observam Figueiredo; Carvalho $^{(3)}$, tendemos a omitir a consciência da sexualidade, criamos um mecanismo de controle, ou como dizem essas autoras, olhamos através de uma cortina de fumaça, que oblitera a visão, para nos desviarmos, deliberadamente, desse assunto que quando focado, é alojado numa perspectiva "patologizante" de risco ou dano à saúde.

Na profundeza do que não é revelado explicitamente, estão contidos os significantes, ou seja as marcas da construção cultural e social que conduzem ao modo singular de cada pessoa vivenciar o mundo.

$\mathrm{O}$ enfoque dado às questões pontuadas, aqui, é fruto de minha vivência como profissional da área da saúde, enquanto enfermeira e docente de enfermagem; de minhas inquietações, enquanto trabalhadora da área da saúde junto a grupos de mulheres; e de leituras, embasadas na antropologia durante o processo de mestrado e doutoramento. Saliento que estas interpretações expressam minha própria visão de mundo que, por sua vez, revela os signos de minha construção cultural, logo não podem ser consideradas verdades absolutas, nem conduzidas como generalidades.

Apresento, aqui, a sexualidade como um fenômeno que faz parte da vida de todas as pessoas, como um evento universal e, ao mesmo tempo, singular a cada indivíduo, já que é uma elaboração específica. Entendo que os corpos são sexuados - possuem algumas características e obedecem a leis de funcionamento biológico -, porém a construção da sexualidade é um processo extremamente complexo ${ }^{(4)}$, que envolve, ao mesmo tempo, aspectos individuais, sociais, psíquicos e culturais que carregam historicidade e envolvem práticas, atitudes e simbolizações.

Essa compreensão acerca da sexualidade tem sido apresentada principalmente em estudos na área da Antropologia, que divulgam esse tema como uma manifestação humana, que sofre modificações quanto ao sentido, função e regulação, de acordo com os diferentes períodos históricos e contextos culturais, e não mais como uma propriedade individual, ou seja, isoladamente ${ }^{(5-8)}$. $\mathrm{Na}$ área da saúde, é bastante comum encontrarmos a concepção de sexualidade reduzida à genitalidade, ao ato sexual, à reprodução, como componente biológico relativo à necessidade meramente orgânica, que tende a classificá-la e normatizá-la com um significado de negação ou afirmação, vale dizer, tende a denominá-la de "normal" ou "anormal"(9).

Penso que, como desafio, é preciso adotar uma nova ótica sobre esse fenômeno humano, possibilitando a interpretação cultural que, atualmente, contempla a expressão das diferenças, da diversidade, das peculiaridades, referentes a um mesmo espaço, a um mesmo tempo. A partir dessa reflexão é possível valorizar a vivência e a historicidade de cada indivíduo, inserido no coletivo social da área da saúde ${ }^{(10-11)}$, tentando reverter num cuidado de enfermagem mais efetivo e, qualitativamente, mais significativo tanto para o enfermeiro cuidador, quanto para o sujeito desse cuidado.

Este artigo acena nesse sentido, apresentando um recorte de minha dissertação de mestrado "A cultura como mediadora da sexualidade da mulher rural"(12), salienta as crenças e os mitos, em relação à sexualidade, de um grupo de mulheres rurais de um município do interior do Rio Grande do Sul e retrata
A sexualidade como uma construção cultural: reflexões sobre preconceitos e mitos inerentes a um grupo de mulheres rurais (a) Essa abordagem faz parte de um debate promovido em mesa redonda na III Jornada Interdisciplinar de Saúde, na Universidade Federal de Santa Maria(UFSM), em setembro de 2001. 
Lúcia Beatriz Ressel Dulce Maria Rosa Gualda como se deu a construção dessa sexualidade a partir do processo de socialização primária.

\section{A METODOLOGIA DO ESTUDO}

A pesquisa referida acima, foi realizada no ano de 1995, junto a um grupo de onze mulheres de uma comunidade rural do município de Restinga Seca, RS. Os critérios de seleção das participantes foram: ser moradora na comunidade escolhida pelo estudo; ser casada ou viver com companheiro fixo; ter vida sexual ativa; e idade entre quinze e cinqüenta anos.

Por meio da técnica de entrevista semiestruturada e individual, foram coletados os dados. As entrevistas foram gravadas em fita cassete, após a autorização das colaboradoras e as narrativas transcritas pela autora do trabalho.

As narrativas foram analisadas de forma qualitativa, buscando, via ótica cultural, o significado dos depoimentos. Embasada em Minayo $^{(13)}$, procedi às seguintes etapas: leitura exaustiva dos depoimentos com conseqüente impregnação das informações aí contidas; categorização dos dados, recortando, no texto, e agrupando as unidades de registro de acordo com suas afinidades temáticas; compreensão e interpretação dos dados, integrando-os ao referencial teórico acerca do tema.

Todas as colaboradoras foram informadas não só dos cuidados éticos que envolviam a pesquisa, tais como: o sigilo, o anonimato e a liberdade em relação a sua participação, mas também do uso e guarda do material coletado. Houve a obtenção de consentimento de todas pelo Termo de Consentimento Livre e Esclarecido (TCLE). Cabe salientar que o projeto da presente pesquisa foi analisado e autorizado pelo Comitê de Ética do Centro de Ciências Rurais, da Universidade Federal de Santa Maria, na oportunidade de sua realização.

\section{CARACTERIZANDO O GRUPO DE COLABORADORAS}

As colaboradoras deste estudo caracterizaram-se por serem mulheres que viviam numa comunidade rural, formada por duzentos e vinte habitantes, organizados em cinqüenta e cinco famílias, que desenvolviam atividades agropecuárias em minifúndios, produzindo arroz, soja e produtos de subsistência para o consumo familiar.

Com exceção de uma das colaboradoras, que era de origem alemã, as demais eram de origem italiana; elas nasceram e se criaram na mesma localidade, ou em outras próximas que culturalmente eram semelhantes a essa localidade.

A religião católica foi um traço homogêneo no grupo, e os valores prescritos pela igreja eram mantidos de maneira não tão rígida quanto a de seus antepassados, mas ainda bem vivenciados nessa comunidade. Como exemplo, a importância dada ao casamento religioso, ao batismo, a rejeição ao divórcio, os conflitos quanto ao uso de anticoncepcionais, a forma de assistirem às missas na igreja, onde as mulheres e os homens sentavam separadamente.

O grupo de colaboradoras era formado por uma maioria de adultos jovens ( $75 \%$ tinha menos de 40 anos), cujos cônjuges também eram jovens. Todas as colaboradoras eram casadas e tinham filhos, sendo a média de dois a três filhos/mulher. Em relação à idade deles, $60 \%$ eram crianças, $28 \%$ eram adolescentes e o restante eram adultos que inclusive não moravam mais com os pais. Foi percebido, nessa informação, como a cultura é um elemento dinâmico ${ }^{(14)}$; pois, embora existam conflitos quanto à aceitação e o uso de anticoncepcionais, advindos de uma orientação católica, essas mulheres faziam uso deles, principalmente da pílula e da laqueadura tubária, havendo muita rejeição quanto ao DIU e ao cóndon, este pelo significado de relação sexual promíscua, aquele pela dúvida de ser ou não abortivo, já que aborto é condenado pela igreja.

Embora essa comunidade se localizasse próxima à sede do município e, também, de centros urbanos maiores; houvesse facilidade de mobilidade às áreas urbanas (todas as colaboradoras possuíam um automóvel da família e possuíam habilitação para dirigir); houvesse facilidade de meios de comunicação, como televisão, rádio e telefone); ainda assim havia nessa comunidade um maior controle social e cultural sobre as mulheres, principalmente, em relação à sexualidade, o que ficou evidenciado na expressão de uma das colaboradoras: "vivemos numa caixinha de fósforo", quando se referia à representação da sua comunidade e à vivência das mulheres no cotidiano e na participação social. São citados como exemplos deste controle: o modo de caminhar delas; de falar, principalmente com homens; a forma como se dirigiam a um vizinho numa roda de conversa; o modo de expor o corpo; o tipo de roupas que usavam (não eram transparentes, curtas, justas ou decotadas); à personalidade extrovertida delas; o aceitar carona de um homem, estando sozinha ou mesmo com 
os filhos, etc. Este controle acontecia em sentido único, isto é, somente dirigido às mulheres.

\section{AS CRENÇAS E OS MITOS REVELADOS NO GRUPO}

Foi percebido, neste estudo, que as mulheres aceitavam o mito da virgindade feminina e o valorizavam, atribuindo-lhe um significado de "valor, objeto de troca, honra". Consideravam tal mito como um "selo de garantia"(15), sendo assim imperativo sua preservação até o casamento.

Entendiam a relação sexual como um compromisso no casamento, portanto, só neste contexto permitida. Havia a concepção de que a relação sexual era uma "necessidade orgânica" para os homens e uma "obrigação" para as mulheres. Essa concepção é constatada por Studart ${ }^{(16)}$, quando se refere às normas, códigos e mitos criados pelos homens para "naturalmente" serem acatados pelas mulheres.

Também emergiu, das narrativas, o mito da passividade e da frigidez feminina, entendido por elas como o resultado de uma rígida e repressora formação sexual, que as impedia de tomar a iniciativa no ato sexual, porque reforçava a idéia de que cabe ao homem as iniciativas. Outras justificativas, advindas de situações de cansaço pelas atividades domésticas executadas ao longo do dia, por fatores externos ou pelo cotidiano familiar, geradores de estresse, eram consideradas causas da a frigidez feminina, esta entendida por elas como uma doença orgânica. Sabemos que a frigidez feminina pode ter causas fisiológicas e psicológicas, mas é preciso ressaltar as causas de ordem cultural, que acabam criando e reforçando rótulos para as mulheres, depreciando-as sexualmente e trazendo um controle à sexualidade delas ${ }^{(16)}$. Nesta comunidade focada, a infidelidade masculina era justificada pelas colaboradoras, que partiam da idéia de que, se a mulher é frígida e o homem tem "necessidade orgânica" de relação sexual, ele deve ser "atendido" de qualquer forma.

Foram narradas, também, situações de exigências constrangedoras criadas para obrigar a mulher a manter relação sexual com seu marido, sem que ela desejasse, semelhante as expostas nos trabalhos ${ }^{(17-19)}$.

Algumas mulheres submetiam-se a isso, entendendo tal tomada de atitude como uma obrigação marital, que evitaria maiores conflitos com o cônjuge; outras conseguiam expressar a falta de desejo e, a partir daí, acon- teciam diálogos entre o casal (em relação a assuntos pertinentes à intimidade matrimonial), e melhorava muito o relacionamento deles em vários aspectos.

Algumas mulheres entendiam que a maternidade e o instinto do amor materno era algo "natural" inerente ao ser feminino, como um papel naturalmente preparado para elas, não como uma função adicional na vida delas, à semelhança do que é discutido no trabalho de Badinter $^{(20)}$ e de Beauvoir ${ }^{(21)}$. Elas imputavam a falta de desejo sexual à maternidade, pois relacionavam o desejo sexual à reprodução, ou seja, para haver uma gravidez, era preciso haver o desejo sexual. Desse modo, elas se reportavam à condição assexuada que a imagem de mãe pode reproduzir nas mulheres ${ }^{(15-16)}$.

Um outro mito muito difundido entre essas mulheres era o referente à menstruação. No grupo pesquisado, as mulheres que tiveram boas experiências com a menarca, vivenciavam sem preconceito o seu período menstrual e mantinham normalmente suas atividades, inclusive as sexuais. Elas entendiam que a menarca representava um rito de passagem para a vida adulta e a possibilidade da maternidade. Já as outras que vinculavam o sangramento menstrual à sujidade, à nojeira, à repugnância ${ }^{(19)}$, o que era mais comum, eram levadas à abstenção sexual nesse período e a outros impedimentos, tais como: não lavar a cabeça, não comer alimentos gelados, não preparar maionese, não ordenhar, dentre outras atividades. Essas atitudes também são confirmadas no estudo de Costa $^{(22)}$.

A situação de desconhecimento sobre a sexualidade na menopausa ${ }^{(23-24)}$, também, foi muito referida nas narrativas. Representando um enigma para a maioria das colaboradoras, ou seja, sendo entendida como um mito, pois vincula o fim da atividade sexual feminina com o fim do período reprodutivo.

Foi constatada uma rejeição muito grande no grupo em relação à masturbação, acordando com os registros de Suplicy ${ }^{(25)}$. Ao mesmo tempo em que as mulheres insinuavam entender o que era, expressavam um desconhecimento a respeito do assunto, pois condenavam essa prática, relacionando-a a algo proibido, a algo errado, que poderia trazer prejuízos físicos e psicológicos. Expressavam o sentimento de vergonha pela substituição ao ato sexual "normal" entre duas pessoas (no caso, homem/mulher). No entanto, algumas mulheres entendiam a masturbação como autocarícia ${ }^{(16)}$ e como conhecimento do próprio corpo; algo que pudes-
A sexualidade como uma construção cultural: reflexões sobre preconceitos e mitos inerentes a um grupo de mulheres rurais 
Lúcia Beatriz Ressel Dulce Maria Rosa Gualda se proporcionar prazer e satisfação. A maioria das narrativas evidenciava a impregnação de valores morais rígidos em relação ao contato com o próprio corpo e, ainda, desconhecimento, medo e preconceitos.

O mito criado e mais rejeitado nesse grupo foi em relação à homossexualidade, entendida como uma anormalidade orgânica e não como uma opção sexual ${ }^{(17)}$.

\section{A CONSTRUÇÃO CULTURAL DA SEXUALIDADE NO GRUPO}

Tentando compreender como se deu a construção da aprendizagem da sexualidade, para esse grupo de mulheres, analisei a relação que elas tiveram com as diversas agências educativas, que as influenciaram culturalmente. Dentre essas verifiquei que, com os pais, havia pouco diálogo e as orientações aos filhos eram dadas como se fossem "alertas" ou "proibições", por meio de repressão, dando-se, assim, o controle social e cultural. Este era diferenciado para meninas e meninos, permitindo para os meninos uma maior liberdade e apresentando para as meninas um maior rigorismo e rigidez. Desse modo, fica confirmada a diferente condição de socialização para homens e mulheres, que aparece em diversos estudos ${ }^{(18-19,26-28)}$.

A igreja, como instituição religiosa, cumpriu seu papel conservador dos valores sociais, por intermédio da impregnação do medo religioso, do pecado. Ela tentou manter a vergonha ligada a tudo que se relacionasse a sexo; defendeu a manutenção da virgindade feminina e a aceitação da relação sexual somente após o casamento, instituindo, dessa forma, o controle da sexualidade feminina. No entanto, a intensidade da ação religiosa sobre o grupo pesquisado foi bem menor do que a ocorrida na geração anterior, contudo influenciou, indiretamente, através dos valores transmitidos na socialização( ${ }^{(29-32)}$.

A escola, como agência educativa, pouco contribuiu para a aprendizagem sexual desse grupo; quando o fez, foi de forma carregada de preconceitos e eventual, não tendo caráter permanente nos currículos. Ela deteve suas informações somente sobre as partes do corpo humano. Quanto à menstruação e gravidez, apenas eram lembrados os perigos do sexo, o que se assemelha ao referido por Saffioti ${ }^{(33)}$, quando estudou a evolução do ensino formal dado às mulheres no Brasil, $o$ qual sugere o reduzido empreendimento e o rigoroso preconceito nessa área.
Outra fonte de aprendizagem informal narrada pelo grupo, porém muito mais ativa e influente, foi a conversa com as amigas (conversas íntimas, particulares ou em turma), favorecendo o amadurecimento, a mudança de comportamento e o esclarecimento dos próprios valores ${ }^{(25)}$.

Entendo que num estudo que envolve uma interpretação cultural, não é pertinente generalizar para não incorrer em discriminações e preconceitos $^{(10-11)}$. Saliento que, nessa descrição bastante sintética optei por apresentar os elementos mais comuns ao comportamento do grupo, procurando não inferir que todas se caracterizavam do mesmo modo. Houve sincretismo, posicionamentos diferentes, contrários, que conviviam no mesmo espaço cultural. Esta pesquisa permitiu a manifestação de particularidades, de diferenças, dentro do universo em que esse grupo de mulheres vivia; permitiu também entender os significados e as interpretações singulares que, em conjunto, formavam uma identidade.

\section{COMENTÁRIOS FINAIS}

A interpretação cultural dos eventos, especialmente sobre a sexualidade, nos subsidia para o cuidado com a pessoa, possibilitando vislumbrá-la como um ser social, cultural e único. No que se refere à sexualidade, é importante não exacerbar o anormal e o patológico, não falar de risco e sim de prazer, não reduzir ao ato sexual e à reprodução, já que tais atitudes facultam a transformação de indivíduos com vivências e histórias singulares, em números, em casos clínicos, em problemas.

Acreditando que cada indivíduo possui sua própria visão de mundo, reforço que a compreensão cultural possibilita a expressão das diferenças, das peculiaridades; valoriza o indivíduo, enquanto sujeito de sua própria vivência; permite a contextualização desse indivíduo e promove um olhar dialético em relação ao nosso agir.

Nesse sentido e conduzido pelos estudos de Heilborn ${ }^{(4,8)}$, este artigo relaciona a sexualidade como um componente cultural de nossa forma de vivenciar o mundo, o que the garante uma dimensão de construção. Finalizando, saliento que a sexualidade é entendida, aqui, como o resultado de uma construção histórica e cultural, que se integra à rede de significados do grupo social específico, possibilitando a manifestação de toda e qualquer expressão relativa ao sexo. Ela é, portanto, uma experiência pessoal, única e marcada profundamente pela cultura em que cada pessoa está imersa, na qual vive. 
(1) Figueiredo NMA. O sentido dos sentidos do corpo de enfermeira no ato de cuidar: o que é e o que não é subjetivo nesta ação: representações de enfermeiras. Rev Enferm UERJ 1995; 3(1):3-9.

(2) Ressel LB, Silva MJP. Reflexões sobre a sexualidade velada no silêncio dos corpos. Rev Esc Enferm USP 2001; 35(2):150-4.

(3) Figueiredo NMA, Carvalho V. O corpo de enfermeira como instrumento de cuidado. Rio de Janeiro: Revinter; 1999.

(4) Heilborn ML. Corpo, sexualidade e gênero. In: Dora DD, organizador. Feminino masculino: igualdade e diferença na justiça. Porto Alegre: Sulina; 1997. p.47-57.

(5) Romero, E. A arquitetura do corpo feminino e a produção do conhecimento. São Paulo: Papirus; 1995. Corpo, cultura e sociedade; p. 235-70.

(6) Bandeira, L. Relações de gênero, corpo e sexualidade. In: Galvão L, Diaz J, organizadores. Saúde sexual e reprodutiva no Brasil. São Paulo: Hucitec; 1999. p.180-97.

(7) Giffin, K. Corpo e conhecimento na saúde sexual: uma visão sociológica. In: Giffin $\mathrm{K}$, Costa SH, organizadores. Questões de saúde reprodutiva. Rio de Janeiro: Fiocruz; 1999. p.79-91.

(8) Heilborn ML. Gênero, sexualidade e saúde. Campinas: Programa de Estudos em Saúde Reprodutiva e Sexualidade - Universidade Estadual de Campinas/ NEPO; 2000 (apostila).

(9) Barbosa RM. Negociação sexual ou sexo negociado? Gênero, sexualidade e poder nos tempos de AIDS. [tese] Rio de Janeiro (RJ): Instituto de Medicina Social da UERJ; 1997.

(10) Featherstone M. O desmanche da cultura: globalização, pós-modernismo e identidade. São Paulo: Studio Nobel/SESC; 1997.

(11) Robertson R. Globalização: teoria social e cultura global. Petrópolis: Vozes; 2000.

(12) Ressel LB. A cultura como mediadora da sexualidade da mulher rural. [dissertação] Santa Maria (RS): Universidade Federal de Santa Maria; 1995.

(13) Minayo MT. O desafio do conhecimento: pesquisa qualitativa em saúde. $2^{\mathrm{a}}$ ed. São Paulo: Hucitec; 1993.

(14) Geertz C. A interpretação das culturas. Rio de Janeiro: LTC; 1989.

(15) Studart H. Mulher, objeto de cama e mesa. $22^{\mathrm{a} e d . ~ P e t r o ́ p o l i s: ~ V o z e s ; ~} 1991$.

(16) Kusnetzoff JC. A mulher sexualmente feliz. $4^{\mathrm{a}}$ ed. Rio de Janeiro: Nova Fronteira; 1988.

(17) Muraro RM. Sexualidade da mulher brasileira: corpo e classe social no Brasil. $3^{\mathrm{a}} \mathrm{ed}$. Petrópolis: Vozes; 1986.
(18) Viezzer M. O problema não está na mulher. São Paulo: Cortez; 1989.

(19) Victora C. Corpo e representações: as imagens do corpo e do aparelho reprodutor feminino. Antropologia do corpo e da saúde II. Cad antropologia/UFRGS 1992; 6:33-53.

(20) Badinter E. Um amor conquistado: o mito do amor materno. Rio de Janeiro: Nova Fronteira; 1985.

(21) Beauvoir S. O segundo sexo. $8^{\mathrm{a} e d .}$ Rio de Janeiro: Nova Fronteira; 1991.

(23) Gonçalves N, Weba S. Sexualidade no climatério. Reprodução 1990; 5(1):21-3.

(22) Costa M. Sexualidade na adolescência: dilemas e crescimento. $4^{\mathrm{a} e d . ~ S a ̃ o ~ P a u l o: ~ L P M ; ~} 1986$.

(24) Trien SF. Menopausa: a grande transformação. $3^{\mathrm{a}}$ ed. Rio de Janeiro: Rosa dos Tempos; 1994.

(25) Suplicy M. Conversando sobre sexo. $17^{\mathrm{a}}$ ed. Petrópolis: Vozes; 1991.

(26) Carneiro S. Identidade feminina. In: Saffioti HIB, Vargas MM, organizadores. Mulher brasileira é assim. Rio de Janeiro: Rosa dos Tempos, Brasília: UNICEF; 1994.

(27) Priore MD. As atitudes da igreja em face da mulher no Brasil-colônia. In: Marcílio ML, organizador. Família, mulher, sexualidade e igreja na história do Brasil. São Paulo: Loyola; 1993.

(28) Muraro RM. Os seis meses em que fui

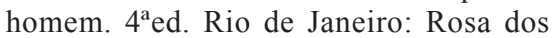
Tempos; 1991.

(29) Azzi R. Família e sexualidade na igreja do Brasil (1930-1964). In: Marcílio ML, organizador. Família, mulher, sexualidade e igreja na história do Brasil. São Paulo: Loyola; 1993.

(30) Vainfas R. Casamento, amor e desejo no ocidente cristão. 2aed. São Paulo: Ática; 1992.

(31) Hoornaert E. A questão do corpo nos documentos da primeira evangelização. In: Marcílio ML, organizador. Família, mulher, sexualidade e igreja na história do Brasil. São Paulo: Loyola; 1993.

(32) Camargo CPF. Família e religião na sociedade rural em mudança. In: Szmrecznyi T, Queda $\mathrm{O}$, organizadores. Vida rural e mudança social: leituras básicas de sociologia rural. São Paulo: Nacional; 1979.

(33) Saffioti HB. A mulher na sociedade de classes: mito e realidade. Petrópolis: Vozes; 1976.
A sexualidade como uma construção cultural: reflexões sobre preconceitos e mitos inerentes a um grupo de mulheres rurais 